\title{
Cranial ultrasound screening in late preterm infants
}

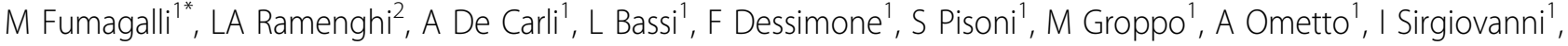 \\ F Mosca $^{1}$
}

From XX National Congress of the Italian Society of Neonatology

Rome, Italy. 9-11 October 2014

Late preterm births have enormously increased in the last decades and there is mounting evidence showing that infants born late preterm are less healthy than infants born at term [1] and they are more likely to develop neonatal morbidities (temperature instability, respiratory distress syndrome, excessive weight loss and dehydration requiring intravenous infusion, sepsis, hypoglycemia and jaundice requiring phototherapy) [2].

More recently, an increased neuromorbidity has been documented and long-term neurodevelopmental impairments (poor school performance, early intervention services, special education needs) have been reported in this population $[3,4]$. The neuromorbidity of the late preterm infants has been attributed to both the potential detrimental neurological effects (extrinsic vulnerability) of the morbidities these babies experience in the neonatal period, and to the intrinsic brain vulnerability. Advances in neuroimaging techniques have highlighted a higher intrinsic vulnerability of the late preterm brain due to the structural and molecular immaturity of the developing brain at specific gestational ages $[5,6]$.

Therefore, late preterm infants have a risk to develop brain lesions which is lower than more premature babies but higher than term newborns and they can be affected by brain lesions common to both preterm and term infants [7]. However, the incidence of brain abnormalities in this specific population has never been investigated as late preterm infants have long been considered a large and low-risk population.

Considering that most of the brain lesions are clinically subtle or silent during the neonatal period, a cranial ultrasound screening may play a role in: 1 . detecting babies at

\footnotetext{
${ }^{1} \mathrm{NICU}$, Department of Clinical Sciences and Community Health, Fondazione IRCCS Cà Granda Ospedale Maggiore Policlinico, Università degli Studi di Milano, Milan, Italy

Full list of author information is available at the end of the article
}

risk of impaired neurodevelopment later in childhood and who may benefit from early intervention programs; 2 . identifying the most significant perinatal risk factors associated with brain abnormalities in such a large low-risk population in order to target the potential need for cranial ultrasound at birth. Based on these assumptions we performed a cranial ultrasound screening project on late preterm infants. Our preliminary data (unpublished data) suggest that lower gestational age, within the late preterm period, and early neonatal morbidities, can provide an indication at birth to undergo a cranial ultrasound scan as they are associated with a higher risk to develop brain abnormalities. Late preterm infants represent a vulnerable population and investigation and follow-up program should be modulated according to the prenatal, perinatal and postnatal characteristics.

Follow-up studies are needed to correlate neonatal ultrasound findings with long-term neurobehavioral outcomes in late preterm infants.

\section{Authors' details}

${ }^{1} \mathrm{NICU}$, Department of Clinical Sciences and Community Health, Fondazione IRCCS Cà Granda Ospedale Maggiore Policlinico, Università degli Studi di Milano, Milan, Italy. ${ }^{2}$ Neonatal Intensive Care Unit, Istituto Giannina Gaslini, Genoa, Italy.

\section{Published: 9 October 2014}

\section{References}

1. Shapiro-Mendoza CK, Lackritz EM: Epidemiology of late and moderate preterm birth. Semin Fetal Neonatal Med 2012, 17(3):120-5.

2. Wang ML, Dorer DJ, Fleming MP, et al: Clinical outcomes of near-term infants. 2004, 114(2):372-6.

3. Shah PE, Robbins N, Coelho RB, et al: The paradox of prematurity: The behavioral vulnerability of late preterm infants and the cognitive susceptibility of very preterm infants at 36 months post-term. Infant Behav Dev 2013, 36(1):50-62.

4. Talge NM, Holzman C, Wang J, et al: Late-preterm birth and its association with cognitive and socioemotional outcomes at 6 years of age. Pediatrics 2010, 126(6):1124-31 
5. Childs AM, Ramenghi LA, Evans DJ, et al: MR features of developing periventricular white matter in preterm infants: evidence of glial cell migration. AJNR 1998, 19(5):971-6.

6. Judaš M, Sedmak G, Kostović I: The significance of the subplate for evolution and developmental plasticity of the human brain. Front Hum Neurosci 2013, 7:423.

7. Sannia A, Natalizia AR, Parodi A, et al: Different gestational ages and changing vulnerability of the premature brain. J Matern Fetal Neonatal Med 2013, [Epub ahead of print].

doi:10.1186/1824-7288-40-S2-A20

Cite this article as: Fumagalli et al: Cranial ultrasound screening in late preterm infants. Italian Journal of Pediatrics 2014 40(Suppl 2):A20.

Submit your next manuscript to BioMed Central and take full advantage of:

- Convenient online submission

- Thorough peer review

- No space constraints or color figure charges

- Immediate publication on acceptance

- Inclusion in PubMed, CAS, Scopus and Google Scholar

- Research which is freely available for redistribution

Submit your manuscript at www.biomedcentral.com/submit 